\title{
Correlação da energia de fratura com parâmetros reológicos de ligantes e mástiques asfálticos
}

\author{
Vivian Silveira dos Santos Bardini ${ }^{1}$, Luis Miguel Gutiérrez Klinsky ${ }^{2}$, \\ José Leomar Fernandes Junior ${ }^{3}$, Reynaldo Roque ${ }^{4}$
}

${ }^{1}$ Instituto de Ciências e Tecnologia, UNESP, vivian.bardini@ict.unesp.br

${ }^{2}$ Centro de Pesquisas Rodoviárias, CCR Nova Dutra, luisgk@outlook.com

${ }^{3}$ Escola de Engenharia de São Carlos, USP, leomar@sc.usp.br

4Universidade da Flórida, UF, rroqu@ce.ufl.edu

\section{Recebido:}

12 de maio de 2016

Aceito para publicação:

23 de dezembro de 2017

Publicado:

30 de abril de 2018

Editor de área:

Francisco Thiago Aragão

\section{Palavras-chaves:}

Fíler mineral,

Mástique asfáltico,

Propriedades reológicas,

Energia de fratura,

Trinca por fadiga.

\section{Keywords:}

Mineral filler,

Asphaltic mastic,

Rheological properties,

Fracture energy.

DOI:10.14295/transportes.v26i1.1150

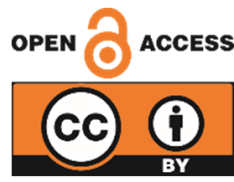

\begin{abstract}
RESUMO
A energia de fratura é uma propriedade relacionada com a contribuição de ligantes asfálticos à resistência à fadiga de misturas asfálticas e, portanto, tem grande influência no comportamento mecânico de pavimentos flexíveis, particularmente no desenvolvimento e propagação de trincas. Esta pesquisa tem o objetivo de contribuir para um meIhor entendimento dos efeitos do fíler mineral e do ligante asfáltico na relação da energia de fratura com os parâmetros reológicos de ligantes e mástiques asfálticos, em temperaturas intermediárias. Para a determinação da energia de fratura foi realizado o ensaio Binder Fracture Energy (BFE), desenvolvido na Universidade da Flórida, em função do tipo e teor do fíler mineral e do ligante asfáltico. Os resultados mostram que a energia de fratura pode ser relacionada com o módulo de cisalhamento dinâmico (G*) e com o ângulo de fase $(\delta)$, obtidos em ensaios no reômetro de cisalhamento dinâmico (DSR), com a rigidez [S(t)] e com a taxa de relaxação $[\mathrm{m}(\mathrm{t})]$, obtidos em ensaios de fluência de viga à flexão (BBR). No entanto, todas as correlações são tênues, reforçando a hipótese de que uma inferência mais adequada sobre o desempenho à fadiga de uma mistura asfáltica pode ser obtida quando a energia de fratura é utilizada juntamente com propriedades fundamentais tradicionais.
\end{abstract}

\begin{abstract}
The fracture energy is a property related to the contribution of asphalt binders to the fatigue resistance of asphalt mixtures and therefore has great influence on the mechanical behavior of flexible pavements, particularly in the development and propagation of cracks. This research aims to contribute to a better understanding of the effects of mineral fillers on the fatigue cracking of asphalt mixtures, at intermediate temperatures, through the Binder Fracture Energy (BFE) test, developed at the University of Florida, with determination of the fracture energy as a function of the type and content of mineral fillers and asphalt binder. The results show that the fracture energy can be related to the dynamic shear modulus ( $\mathrm{G}^{*}$ ) and phase angle $(\delta)$, obtained from tests in the dynamic shear rheometer (DSR), and with the stiffness [S $(t)]$ and the relaxation modulus [ $\mathrm{m}(\mathrm{t})]$, obtained from tests in the bending beam rheometer (BBR). Howevver, all correlations are weak, reinforcing the hypothesis that the best way to predict the fatigue performance of an asphalt is using fundamental properties, like the fracture energy.
\end{abstract}

\section{INTRODUÇÃO}

O comportamento mecânico de misturas asfálticas é influenciado por diversos fatores, sendo um deles a resistência à fadiga dos ligantes asfálticos. Roque et al. (2009) argumentam que alguns ensaios de ligantes asfálticos, incluindo o de Cisalhamento em Regime Oscilatório (DSR), a Recuperação Elástica por Torção (ER) e o Retorno Elástico por Ductilidade (FD) não são capazes de prever o desempenho dos 
pavimentos asfálticos em termos de trincamento sob temperaturas intermediárias de maneira tão precisa quanto os ensaios que determinam a energia de fratura do ligante asfáltico. Outros autores também apontaram limitações dos índices Superpave, podendo-se citar Bahia et al. (2008), os quais afirmam que o parâmetro $G^{*}$ sen $\delta$ reflete apenas o comportamento viscoelástico linear e negligencia o comportamento viscoelástico não linear. Para Walker (2016) o parâmetro Superpave para temperaturas intermediárias, $\mathrm{G}^{*} \mathrm{sen} \delta$, se correlaciona fracamente com a fadiga da mistura asfáltica.

A energia de fratura é definida como a quantidade de energia necessária para criar uma unidade de trinca (Romeo, 2008), sendo uma propriedade fundamental, ou seja, independente do estado de tensões ou condições de carregamento (Koh e Roque, 2010). De uma maneira geral, a determinação da energia de fratura dos componentes de uma mistura asfáltica (agregados e ligantes asfálticos) pode ser utilizada no projeto estrutural de pavimentos, sendo a energia de fratura do ligante asfáltico particularmente influente para a previsão da resistência à fadiga das misturas asfálticas.

A determinação da energia acumulada até a ruptura em ensaios realizados com ligantes asfálticos pode ser útil para a previsão do desenvolvimento das trincas sob temperaturas intermediárias, fornecendo parâmetros relacionados com a resistência à fadiga de misturas asfálticas. Como o dano por fadiga está fortemente relacionado com as características do ligante asfáltico, as propriedades do fíler e a interação entre fíler mineral e ligante asfáltico têm efeito no desenvolvimento e propagação das microfissuras no mástique (Kim et al., 2003).

Para a avaliação das propriedades de fratura de ligantes asfálticos têm sido utilizados, tradicionalmente, os ensaios com o Reômetro de Cisalhamento Dinâmico (DSR), com determinação do módulo de cisalhamento dinâmico $\left(G^{*}\right)$ e do ângulo de fase $(\delta)$, além de parâmetros derivados desses ensaios, como a energia e deformação produzidas na tensão máxima. Outros ensaios ainda podem ser citados, como o realizado no Reômetro de Flexão em Viga (BBR), com a determinação da rigidez [S(t)] e da taxa de relaxação [m(t)], além da Recuperação Elástica e da Ductilidade (Bahia, 2010).

Durante os estudos de misturas asfálticas do Programa SHRP (Superior Performing Pavements), o trincamento térmico a baixas temperaturas foi considerado um fator importante, por ser um dos mecanismos de ruptura em pavimentos. Assim, baseado nas considerações práticas, dois ensaios foram adotados nas especificações para ligantes asfálticos, a fim de caracterizar as propriedades a baixa temperatura. No ensaio empregando o Reômetro de Viga à Flexão (BBR) são avaliadas as propriedades reológicas e no Ensaio de Tração Direta (DTT) são caracterizadas as propriedades de fratura de ligantes asfálticos (Anderson e Dongré, 1995).

Conceitualmente, o Ensaio de Tração Direta (DTT) permite a determinação da energia de fratura de ligantes asfálticos. Porém, os resultados do DTT na sua configuração atual apresentam grande variabilidade, devido ao formato do corpo de prova, que não representa apropriadamente as condições de ruptura dos ligantes asfálticos entre os agregados na mistura. Outro motivo da variabilidade dos resultados do DTT é a quase uniformidade da tensão de tração ao longo da seção central, com possibilidade de ruptura em qualquer ponto dessa seção, o que dificulta a medida exata da tensão no plano de ruptura, necessária para a determinação da energia de fratura.

Anderson e Dongré (1995) argumentam que o DTT não é válido para deformações acima de 10\%, que ocorrem quando há aumento da temperatura e redução da taxa de elongamento; os autores citam a necessidade da correção em razão da redução da seção transversal, já que a fratura do ligante seria causada pelo escoamento do corpo de prova e não pela ruptura. 0 ensaio foi projetado para o espectro de tensões dentro da ruptura frágil, ou seja, com propagação rápida de trincas, com uma deformação plástica muito pequena ou nula; quando escoamento do corpo de prova e consequente redução da seção transversal, a ruptura que ocorre é a dúctil, em que ocorre apenas após deformação plástica extensa.

Ponniah et al. (1996) propôs uma especificação de energia de fratura para ligantes asfáltico modificados, em que utilizaram o método de flexão em viga de três pontos para determinar a tenacidade de fratura e com isso calcularam a energia de fratura baseada na tenacidade (energia total que o material pode absorver até a ruptura, por unidade de volume). Anderson et al. (2001) realizaram o ensaio de 
flexão de três pontos no BBR para vários ligantes asfálticos e descobriram que a tenacidade na fratura fornece uma classificação muito mais exigente da resistência ao trincamento térmico que o critério Superpave. Hoare e Hesp (2000) analisaram os resultados do ensaio de viga a flexão de três pontos e contataram que a tenacidade de fratura e a energia de fratura são dependentes da morfologia do ligante asfáltico, do teor de polímero e da rigidez. Porém, esse método é adequado apenas para asfaltos que apresentem ruptura frágil, ou seja, sob baixas temperaturas, circunstância em que se aplica a Mecânica da Fratura Elástico-Linear, mas não é aplicável a ligantes asfálticos com ruptura dúctil, ou seja, sob temperaturas intermediárias.

Pesquisadores da Universidade da Flórida (Roque et al., 2012) desenvolveram um ensaio para determinação da energia acumulada até a ruptura, utilizando o DTT, mas com um método específico de interpretação dos dados. 0 ensaio permite a determinação da energia de fratura sob temperaturas intermediárias e, assim, é capaz de avaliar o comportamento do ligante asfáltico ao trincamento por fadiga. 0 novo procedimento foi avaliado em ensaios realizados com ligantes puros e com ligantes modificados em diferentes temperaturas e taxas de carregamento.

A geometria do corpo de prova utilizada para o ensaio proposto por Roque et al. (2012) (Binder Fracture Energy - BFE) é apresentada na Figura 1. A análise em Elementos Finitos mostra que há uma concentração de tensão superior a cinco vezes a tensão aplicada pelo carregamento, suficiente para resultados consistentes de fratura na seção transversal central, ou seja, assegurando que a ruptura ocorre nesta seção.
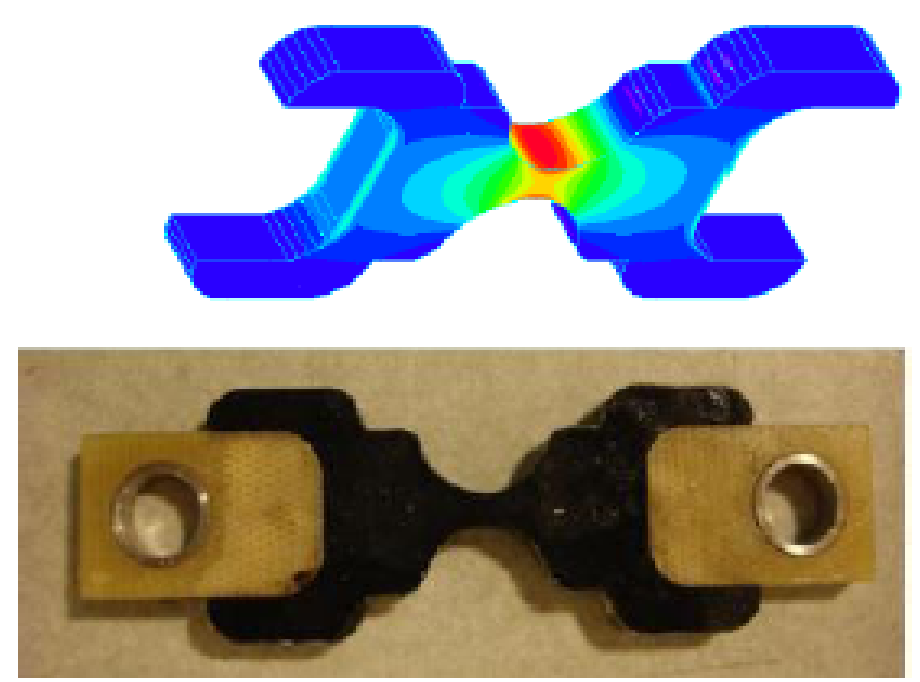

Figura 1: Geometria do corpo de prova e tensões no Ensaio Binder Fracture Energy (BFE) Fonte: Roque et al. (2012)

A análise estatística dos ensaios realizados por Roque et al. (2012) mostrou que o ensaio distingue diferentes ligantes asfálticos por meio da energia de fratura e que, para um dado ligante asfáltico, a energia de fratura é independente da taxa de carregamento e da temperatura de ensaio, constituindo uma propriedade fundamental de um ligante asfáltico, ou seja, independente das condições de ensaio.

O novo método de ensaio, chamado Binder Fracture Energy (BFE) desenvolvido na Universidade da Flórida foi avaliado em diversos outros trabalhos (Niu et al., 2014; Niu et al., 2015), porém não foi avaliado para mástiques asfálticos, que condicionam o desempenho de uma mistura asfáltica no campo, devendo ser mais bem estudadas.

Esta pesquisa visa contribuir para um melhor entendimento dos efeitos do fíler mineral e do ligante asfáltico na relação da energia de fratura com os parâmetros reológicos de ligantes e mástiques asfálticos, em temperaturas intermediárias, fornecendo dados para o estudo do trincamento por fadiga nessa faixa de temperatura. 


\section{OBJETIVOS}

O principal objetivo deste estudo é correlacionar os dados de energia de fratura de mástiques asfálticos com os parâmetros reológicos, o módulo complexo $\left(\mathrm{G}^{*}\right)$, o ângulo de fase $(\delta)$, a rigidez $[\mathrm{S}(60)]$ e a taxa de relaxação [m(60)].

A avaliação da energia de fratura foi realizada pelo Ensaio Binder Fracture Energy (BFE), e os ensaios, tanto de energia de fratura quanto com o Reômetro de Cisalhamento Direto (DSR) e com o Reômetro de Fluência de Viga à Flexão (BBR), foram realizados em ligantes e mástiques asfálticos compostos por diferentes fileres minerais, diferentes ligantes asfálticos e diferentes razões fíler/asfalto.

\section{MATERIAIS E MÉTODOS}

\subsection{Materiais utilizados}

Para a produção dos mástiques asfálticos, foram utilizados dois tipos de ligante asfáltico, um Cimento Asfáltico de Petróleo (CAP) 50/70 e um CAP 85/100. A Tabela 1 apresenta as propriedades físicas de ambos. Foram avaliados três fíleres: cal hidratada, cimento Portland e pó de calcário. Os resultados da determinação da massa específica real dos fileres, realizada conforme o procedimento DNER-ME 085/94, estão apresentados na Tabela 2, que também apresenta os valores médios de superfície específica, obtido segundo o procedimento proposto por Pinnila (1965).

Os fíleres de cimento Portland e pó calcário foram utilizados na relação fíler/asfalto (f/a) de 0,6 e 1,2, enquanto o fíler de cal hidratada foi ensaiado com f/a de 0,3 e 0,6. Vale citar que neste trabalho fíler é o material $100 \%$ passante na peneira de $0,075 \mathrm{~mm}$ de abertura (\# 200).

A Faixa C do DNIT prescreve um percentual de material passante na \# 200 entre de 2 a 10\%. Uma mistura com $1,5 \%$ de cal, para um teor de ligante asfáltico de projeto de $5 \%$, resulta na relação de $1,5 / 5$, equivalente a f/a de 0,3. Raramente as misturas asfálticas empregam teores de cal superiores a 3\%, isto é relações de f/a superiores a 0,6 , logo não justifica neste estudo avaliar relações superiores, como foi o caso dos fíleres minerais.

Tabela 1: Propriedades Físicas dos Ligantes Asfálticos

\begin{tabular}{|c|c|c|c|c|c|c|}
\hline \multirow[b]{2}{*}{ Propriedade } & \multirow[b]{2}{*}{$\begin{array}{l}\text { Método } \\
\text { ASTM }\end{array}$} & \multicolumn{2}{|c|}{ Especificação } & \multicolumn{2}{|c|}{ Resultado } & \multirow[b]{2}{*}{ Unidade } \\
\hline & & CAP 50/70 & CAP 85/100 & $\begin{array}{l}\text { CAP } \\
50 / 70\end{array}$ & CAP 85/100 & \\
\hline Penetração & D 5 & 50 a 70 & 85 a 100 & 50 & 102 & $0,1 \mathrm{~mm}$ \\
\hline Ponto de Amolecimento & D 36 & $>46$ & $>43$ & 48,6 & 43,5 & ${ }^{\circ} \mathrm{C}$ \\
\hline Viscosidade Brookfield @ $135^{\circ} \mathrm{C}$ & D 4402 & $274 \min$ & $214 \min$ & 377 & 252,5 & $\mathrm{CP}$ \\
\hline Viscosidade Brookfield @150C & D 4403 & $112 \min$ & $97 \mathrm{~min}$ & 187 & 130 & $\mathrm{CP}$ \\
\hline Viscosidade Brookfield @177C & D 4404 & 57 a 285 & 28 a 114 & 69 & 52.5 & $c P$ \\
\hline
\end{tabular}

Tabela 2: Massa Específica Real (dos sólidos) e Superfície Específica ( $\mathrm{S}_{\mathrm{e}}$ ) dos Fíleres

\begin{tabular}{|c|c|c|}
\hline Material & Massa Específica $\left(\mathrm{g} / \mathrm{cm}^{3}\right)$ & $S_{e}\left(\mathrm{~cm}^{2} / \mathrm{g}\right)$ \\
\hline Pó de Calcário & 2,749 & $2800-3500$ \\
\hline Cal Hidratada (Cálcica) & 2,350 & $5000-15000$ \\
\hline Cimento Portland & 3,030 & $2200-2750$ \\
\hline
\end{tabular}

\subsection{Métodos de Ensaio}

Os ensaios foram realizados em ligantes e mástiques asfálticos virgens e envelhecidos (longo prazo). Devido à falta de padronização do envelhecimento de mástiques, foram adotados dois procedimentos, ambos utilizando a Estufa de Vaso Pressurizado (PAV): 1. procedimento convencional de envelhecimento de ligantes asfálticos (a longo prazo), mantendo-se a amostra a $100^{\circ} \mathrm{C}$ por 20 horas; e 2. procedimento modificado, mantendo-se a amostra a $60^{\circ} \mathrm{C}$ por 100 horas, remisturando o mástique a cada 20 horas, mantendo-se a pressurização durante todo o ensaio $(100 \mathrm{~h})$, despressurizando apenas para retirar a amostra e remisturar o material. 
No ensaio de envelhecimento no PAV o ligante asfáltico fica distribuído em recipientes metálicos de forma estática. Esse sistema funciona razoavelmente bem para ligantes asfálticos convencionais e modificados. No entanto, para envelhecimento de mástiques asfálticos, que possuem carga mineral, há suspeita que, na temperatura do ensaio, aconteça uma separação das partículas minerais. Dessa forma, o envelhecimento sucederia apenas no ligante asfáltico e não no mástique asfáltico. Portanto optou-se também em avaliar o procedimento de reduzir a temperatura, e incrementar o tempo de envelhecimento, com intervalos nos quais o mástique asfáltico era re-homogeneizado, para garantir a distribuição das partículas minerais na matriz asfáltica.

Vários autores (Hung et al., 2002; Huang e Zeng, 2007; Huang et al., 2001) pesquisaram sobre a melhor combinação de temperatura e tempo de ensaio na Estufa de Vaso Pressurizado para amostras com fíler para simular o envelhecimento a longo prazo em campo. A maior parte deles concluiu que a temperatura de $60^{\circ}$ é adequada para que não haja separação da parte sólida (mineral) da viscoelástica (ligante), e os tempos entre 20 e 100 horas provocam envelhecimento muito semelhante ao que ocorre no campo.

Os corpos de prova foram moldados para o ensaio BFE de acordo com o procedimento AASHTO T 314-02, que prescreve a preparação de amostras de ligante asfáltico para o ensaio no DTT. 0 ensaio foi realizado de acordo com o procedimento proposto por Roque et al. (2012) e descrito por Bardini (2013).

A preparação da amostra consiste em aquecer o ligante ou o mástique asfáltico até que esteja liquido o suficiente para fluir adequadamente. Os moldes devem ser aquecidos aproximadamente na mesma temperatura do ligante asfáltico (Figura 2 (a)), por aproximadamente 3 minutos. Os moldes devem ser colocados em uma base para moldagem preparada com material antiaderente sendo que as paredes internas do molde também recebem o produto antiaderente, como glicerina, para que o desmolde seja realizado sem deformação do corpo de prova. A amostra deve ser colocada com excesso nos moldes, sendo deixada resfriar por, no mínimo 30 minutos. Ao final, apara-se a amostra com uma espátula aquecida, sendo que a configuração final deve ser de acordo com a Figura 2 (b).

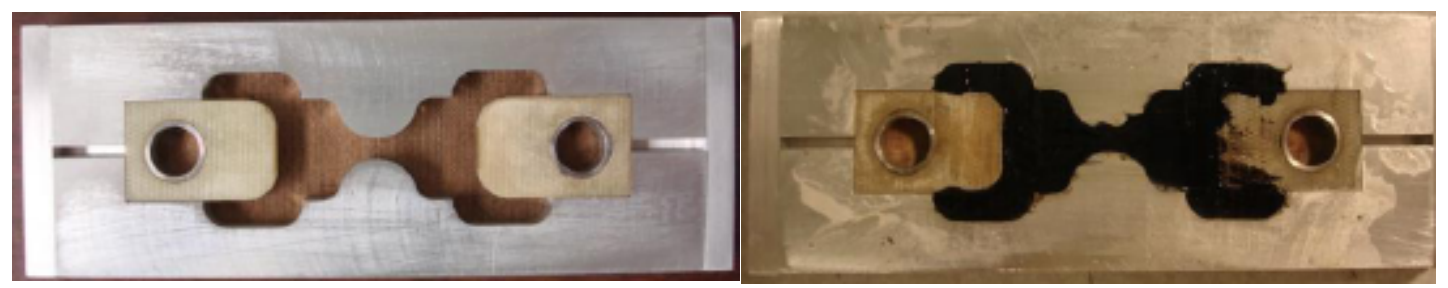

Figura 2: (a) Molde para o corpo de prova do ensaio BFE, (b) Configuração final do molde com o corpo de prova

Em seguida, os corpos de prova, ainda nos moldes, devem ser colocados na estufa de temperatura controlada, dentro da prensa universal. Esse conjunto deve permanecer na temperatura de ensaio durante, no mínimo, 4 horas, para estabilização da temperatura.

Para que o resultado de um ensaio seja aceitável, há uma combinação ótima de faixa de temperatura e taxa de carregamento para se obter a energia de fratura; existem condições para que o tipo de ruptura seja apropriado, ou seja, para cada tipo de ligante asfáltico há uma taxa de carregamento apropriada para diferentes temperaturas, evitando-se a ruptura prematura.

Quando ocorre a ruptura prematura, a energia de fratura correspondente é muito pequena (perto de zero). Adicionalmente à observação visual, a ruptura prematura pode ser identificada pela ocorrência de uma curva tensão-deformação incompleta, como pode ser observado na Figura 3, no (a) aspecto do corpo de prova e na (b) curva tensão-deformação (ROQUE et al., 2012).

Também pode ocorrer a ruptura após uma deformação muito elevada do corpo de prova, condição não adequada para o ensaio, pois a análise de elementos finitos não-linear pode ser utilizada até certo nível de deformação. Fraturas dúcteis exibem o estreitamento no centro do corpo de prova, devido à 
grande deformação na ruptura, e a análise de elementos finitos não é adequada para simular esse tipo de ruptura, mesmo com a utilização da formulação de grandes deformações (ROQUE et al., 2012). A Figura 4 mostra um exemplo de fratura apropriada (a) do ensaio de energia de fratura, com as correspondentes curvas tensão-deformação (b).

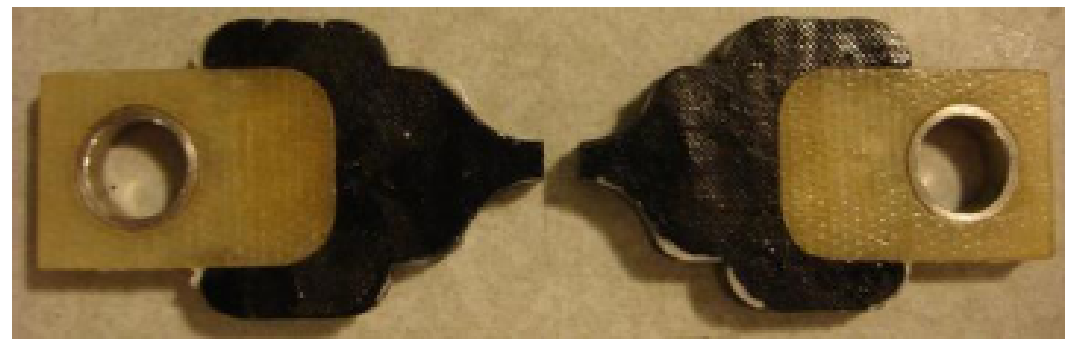

(a)

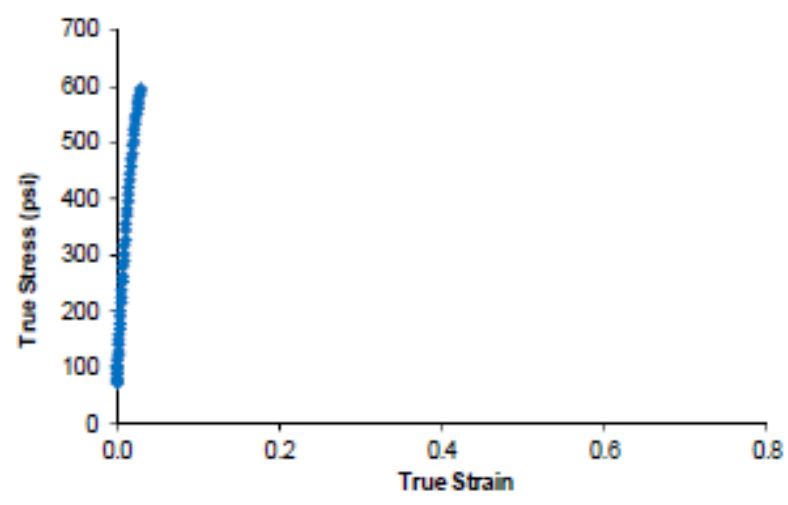

(b)

Figura 3: Exemplo de fratura do corpo de prova no ensaio $\mathrm{BFE}$, com fratura prematura

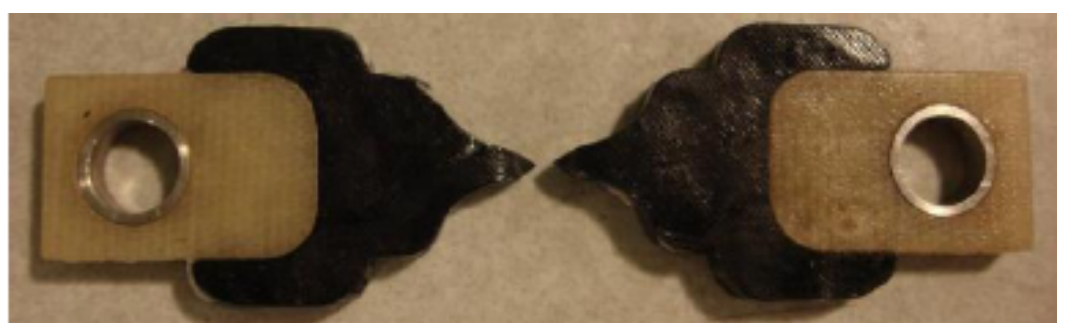

(a)

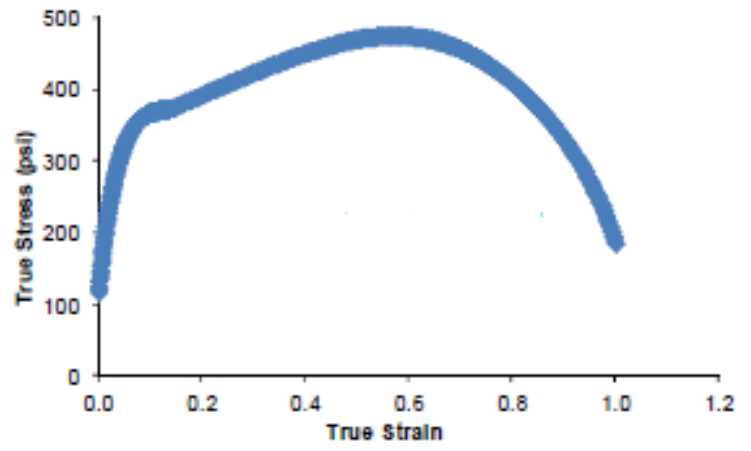

(b)

Figura 4: Exemplo de fratura do corpo de prova no ensaio BFE, com fratura apropriada 
A combinação de temperaturas e taxas de carregamento utilizadas para cada amostra está mostrada na Tabela 3 e 4, para os ligantes e mástiques asfálticos compostos com o CAP 50/70 e CAP 85/100, respectivamente.

Tabela 3: Temperaturas e Taxas de Carregamento utilizadas nos ensaios BFE para os mástiques asfálticos composto com CAP 50/70

\begin{tabular}{|c|c|c|c|c|}
\hline Tipo de Fíler & $f / a$ & Envelhecimento & Temperatura $\left({ }^{\circ} \mathrm{C}\right)$ & Taxa de carregamento $(\mathrm{mm} / \mathrm{min})$ \\
\hline \multirow{3}{*}{ sem filer } & \multirow{3}{*}{0,0} & sem evelhecimento & 10 & 150 \\
\hline & & Convencional & 15 & $150 ; 200$ \\
\hline & & Modificado & 15 & $150 ; 200$ \\
\hline \multirow{6}{*}{$\begin{array}{l}\text { cimento } \\
\text { Portland }\end{array}$} & \multirow{3}{*}{0,6} & sem evelhecimento & $15 ; 20$ & $400 ; 700 ; 800$ \\
\hline & & Convencional & $15 ; 20$ & $200 ; 250 ; 500 ; 600 ; 700$ \\
\hline & & Modificado & 15 & $150 ; 200 ; 250 ; 300$ \\
\hline & \multirow{3}{*}{1,2} & sem evelhecimento & $15 ; 20$ & $50 ; 100 ; 150 ; 200 ; 250 ; 300$ \\
\hline & & Convencional & $15 ; 25$ & $100 ; 400 ; 600 ; 700$ \\
\hline & & Modificado & 20 & $50 ; 75 ; 100$ \\
\hline \multirow{6}{*}{ pó calcário } & \multirow{3}{*}{0,6} & sem evelhecimento & 15 & $400 ; 500$ \\
\hline & & Convencional & $15 ; 20$ & $100 ; 150 ; 400 ; 500 ; 600 ; 700$ \\
\hline & & Modificado & 15 & $100 ; 200 ; 250$ \\
\hline & \multirow{3}{*}{1,2} & sem evelhecimento & 20 & $250 ; 300 ; 350$ \\
\hline & & Convencional & $20 ; 25$ & $50 ; 100 ; 150 ; 300 ; 500 ; 600$ \\
\hline & & Modificado & 20 & $150 ; 200 ; 250$ \\
\hline \multirow{6}{*}{ cal hidratada } & \multirow{3}{*}{0,3} & sem evelhecimento & $15 ; 20$ & $200 ; 250 ; 300 ; 500 ; 600 ; 700$ \\
\hline & & Convencional & $15 ; 20$ & $100 ; 150 ; 400 ; 500 ; 600 ; 700$ \\
\hline & & modificado & 15 & $75 ; 100 ; 150$ \\
\hline & \multirow{3}{*}{0,6} & sem evelhecimento & $15 ; 20$ & $25 ; 100 ; 150$ \\
\hline & & convencional & $20 ; 25$ & $50 ; 75 ; 100 ; 200 ; 400 ; 600$ \\
\hline & & modificado & 20 & $75 ; 100 ; 150$ \\
\hline
\end{tabular}

Nota: envelhecimento convencional: 20 horas a 100C; envelhecimento modificado: 100 horas a 60 C

Tabela 4: Temperaturas e Taxas de Carregamento utilizadas nos ensaios BFE para os mástiques asfálticos compostos com o CAP $85 / 100$

\begin{tabular}{|c|c|c|c|c|}
\hline $\begin{array}{l}\text { Tipo de } \\
\text { Fíler }\end{array}$ & $f / a$ & Envelhecimento & Temperatura $\left({ }^{\circ} \mathrm{C}\right)$ & Taxa de carregamento $(\mathrm{mm} / \mathrm{min})$ \\
\hline \multirow{3}{*}{ sem filer } & \multirow{3}{*}{0,0} & sem evelhecimento & 10 & $600 ; 700$ \\
\hline & & convencional & 15 & $400 ; 500$ \\
\hline & & modificado & 15 & $300 ; 400$ \\
\hline \multirow{6}{*}{$\begin{array}{l}\text { cimento } \\
\text { Portland }\end{array}$} & \multirow{3}{*}{0,6} & sem evelhecimento & $10 ; 15$ & $200 ; 300 ; 400 ; 500 ; 600$ \\
\hline & & convencional & 15 & $300 ; 400 ; 500 ; 600$ \\
\hline & & modificado & 15 & $300 ; 400 ; 500$ \\
\hline & \multirow{3}{*}{1,2} & sem evelhecimento & $10 ; 15$ & $50 ; 100 ; 200 ; 250$ \\
\hline & & convencional & 15 & $50 ; 75 ; 100 ; 150$ \\
\hline & & modificado & 15 & $75 ; 100$ \\
\hline \multirow{6}{*}{ pó calcário } & \multirow{3}{*}{0,6} & sem evelhecimento & $10 ; 15$ & $300 ; 400 ; 500 ; 700 ; 800 ; 1000$ \\
\hline & & convencional & 15 & $400 ; 500 ; 600$ \\
\hline & & modificado & 15 & $500 ; 600 ; 700$ \\
\hline & \multirow{3}{*}{1,2} & sem evelhecimento & $10 ; 15$ & $75 ; 100 ; 150 ; 250 ; 300 ; 400 ; 500$ \\
\hline & & convencional & 15 & $50 ; 75 ; 100$ \\
\hline & & modificado & 15 & $100 ; 150 ; 200$ \\
\hline \multirow{6}{*}{ cal hidratada } & \multirow{3}{*}{0,3} & sem evelhecimento & $10 ; 15$ & $100 ; 200 ; 300 ; 500$ \\
\hline & & convencional & 15 & $300 ; 400 ; 500$ \\
\hline & & modificado & 15 & $400 ; 500 ; 600$ \\
\hline & \multirow{3}{*}{0,6} & sem evelhecimento & $10 ; 15$ & $75 ; 150 ; 100 ; 250$ \\
\hline & & convencional & 15 & $50 ; 75 ; 100$ \\
\hline & & modificado & 15 & $100 ; 150$ \\
\hline
\end{tabular}

Nota: envelhecimento convencional: 20 horas a 100C; envelhecimento modificado: 100 horas a 60 C 
0 ensaio de cisalhamento em regime oscilatório, utilizando-se mástique asfáltico virgem, foi realizado de acordo com a norma ASTM D 7175 - 05, enquanto que o ensaio de fluência de viga a flexão, utilizandose mástiques asfálticos envelhecidos (processo convencional e processo modificado), foi realizado de acordo com a norma ASTM D 6648 - 01. Os ensaios no DSR foram realizados com os mástiques asfálticos compostos por cimento Portland e por pó calcário nas relações f/a de 0,6 e 1,2 e por cal hidratada nas relações f/a de 0,3 e 0,6. Os ensaios no BBR foram feitos com os mástiques produzidos com relações f/a de 0,6 e 1,2 para o cimento Portland e para o pó calcário e relações f/a de 0,3 e 0,6 para a cal hidratada.

Os valores de módulo complexo $\left(\mathrm{G}^{*}\right)$ e ângulo de fase $(\delta)$ foram obtidos na temperatura de $25^{\circ} \mathrm{C}$ e $10 \mathrm{rad} / \mathrm{s}$; e os valores de módulo de rigidez e taxa de relaxação no tempo de carregamento de 60 segun$\operatorname{dos}[\mathrm{S}(60)$ e $\mathrm{m}(60)]$, na temperatura de $-12^{\circ} \mathrm{C}$.

\section{RESULTADOS}

\subsection{Ensaio Binder Fracture Energy (BFE)}

A Figura 5 mostra a média, de no mínimo três medidas, dos resultados de energia de fratura para os mástiques compostos com o CAP 50/70 e pelos fileres de cimento Portland, pó calcário e cal hidratada, sem envelhecimento, envelhecimento convencional no PAV $\left(20\right.$ horas a $\left.100^{\circ} \mathrm{C}\right)$ e envelhecimento modificado no PAV (100 horas a $\left.60^{\circ} \mathrm{C}\right)$.

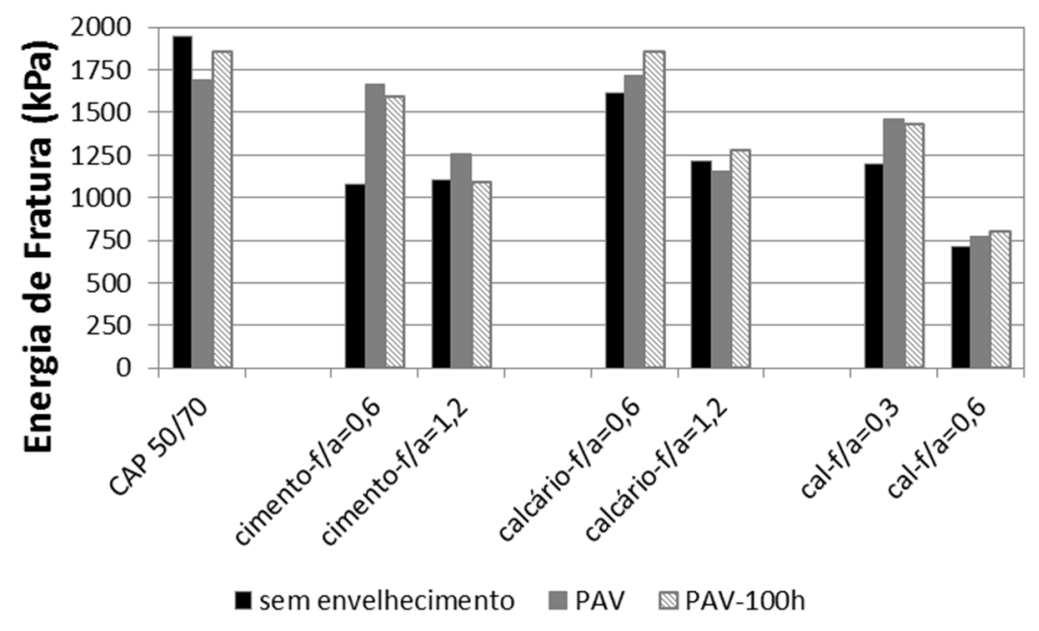

Figura 5: Energia de Fratura de mástiques compostos com o CAP 50/70

Pode-se notar que a adição de fíler ao ligante asfáltico diminui a energia de fratura, reduzindo a resistência ao trincamento em temperaturas intermediárias. Por sua vez, o aumento do teor de fíler também colabora para reduzir a energia de fratura, exceto para o fíler de cimento Portland sem envelhecimento. 0 envelhecimento diminui a energia de fratura do ligante asfáltico, porém aumenta a energia de fratura dos mástiques, exceto para o composto pelo fíler de pó calcário na relação f/a de 1,2. Pode-se notar que nos mástiques compostos pelo cimento Portland e por cal hidratada, o aumento da energia de fratura é maior nos mástiques com menor relação f/a.

Ambos os procedimentos de envelhecimento no PAV diminuem a energia de fratura do ligante asfáltico, mas o procedimento modificado promove menor diminuição da energia de fratura que o procedimento convencional. 0 envelhecimento aumenta a energia de fratura de mástiques com baixa relação f/a, porém o tipo de envelhecimento não influencia os valores de energia de fratura. Os dois tipos de envelhecimento conduzem a diferentes comportamentos nos mástiques com maiores teores de fíler, como, por exemplo, os mástiques preparados com cimento Portland, na relação f/a de 1,2, em que o procedimento convencional aumentou a energia de fratura e o modificado não alterou a energia de fratura. 
A Figura 6 mostra a média, de pelo menos três ensaios, dos valores de energia de fratura dos mástiques compostos com CAP 85/100 e os fileres de cimento Portland, pó calcário e cal hidratada, sem envelhecimento, envelhecimento convencional no PAV e envelhecimento modificado no PAV. Igualmente ao que ocorreu para os mástiques compostos pelo CAP 50/70, a energia de fratura diminuiu tanto com a adição de fíler quanto com o aumento da relação f/a, agora inclusive para o fíler de cimento Portland sem envelhecimento.

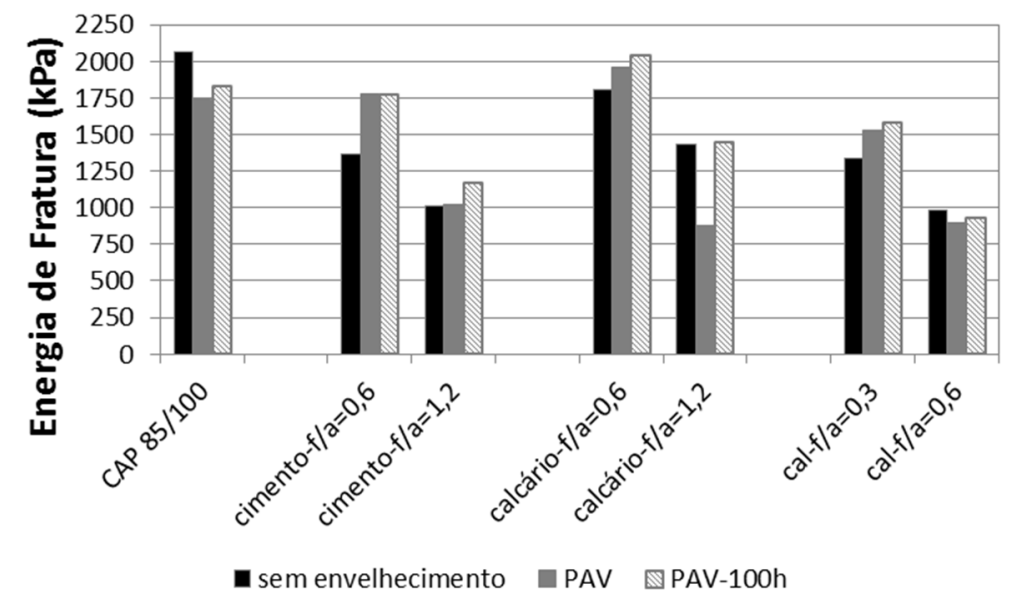

Figura 6: Energia de Fratura de mástiques compostos com CAP 85/100

Pode-se notar que o envelhecimento diminui a energia de fratura do ligante asfáltico, porém aumenta a energia de fratura dos mástiques, exceto pelo composto por fíler de pó calcário na relação f/a de 1,2 e para a cal hidratada na relação f/a de 0,6. Com o fíler de cimento Portland o aumento da energia de fratura é maior para baixas concentrações de fíler. Ambos os procedimentos de envelhecimento diminuem os valores de energia de fratura do ligante asfáltico, mas o procedimento modificado provoca uma menor diminuição da energia de fratura do que o procedimento convencional, como foi notado para o CAP 50/70. 0 procedimento do PAV modificado aumenta a energia de fratura dos mástiques, exceto para o composto pela cal hidratada na relação f/a de 0,6.

Os resultados da energia de fratura dos ligantes asfálticos puros (CAP 50/70 e CAP 85/100) e dos mástiques asfálticos sem envelhecimento mostram que a adição de maiores teores de fíler diminui os valores de energia de fratura. Sendo a energia de fratura uma propriedade relacionada à resistência à fadiga de ligantes asfálticos, relações f/a maiores pode significar uma diminuição da resistência ao trincamento em temperaturas intermediárias.

As tendências de redução de energia de fratura são similares nas amostras virgens e nas amostras envelhecidas, porém a adição de fíler produz uma menor redução da energia de fratura nas amostras envelhecidas.

Assim, o efeito do envelhecimento é menos severo nos mástiques do que no ligante asfáltico puro, para baixos teores de fíler (relação f/a de 0,6 para cimento Portland e pó calcário, e de 0,3 para cal hidratada). Para maiores teores de fíler, os valores de energia de fratura para mástiques envelhecidos são próximos aos das amostras sem envelhecimento. 0 envelhecimento ameniza a redução da energia de fratura, especialmente nas relações f/a mais altas, o que pode indicar menor sensibilidade ao envelhecimento nos mástiques asfálticos.

As amostras envelhecidas no PAV modificado mostraram o mesmo comportamento observado para as amostras envelhecidas no PAV convencional e os maiores valores de energia de fratura foram obtidos quando o fíler de cal hidratada foi utilizado. Os procedimentos PAV convencional e PAV modificado pro- 
duziram envelhecimento muito similar nos ligantes e mástiques asfálticos, à luz dos resultados de energia de fratura. Em ambos os casos, o mástique asfáltico com cal hidratada apresentou maior energia de fratura após envelhecimento, quando comparado com o resultado obtido na amostra virgem.

\subsection{Reômetro de Cisalhamento Dinâmico (DSR)}

A Tabela 5 mostra os resultados de módulo complexo $\left(\mathrm{G}^{*}\right)$ e de ângulo de fase $(\delta)$ obtidos em ensaios realizados no Reômetro de Cisalhamento Dinâmico (DSR), a $25^{\circ} \mathrm{C}$ e frequência de $10 \mathrm{rad} / \mathrm{s}$, para ligantes asfálticos e mástiques sem envelhecimento. A adição de fíler mineral aos ligantes asfálticos aumenta os valores de $\mathrm{G}^{*}$ e, quanto maior o teor de fíler, maior o módulo complexo; a Figura 7 mostra o aumento do G* em função do tipo e teor de fíler, para o CAP 50/70 (a) e para o CAP 85/100. A adição de cal hidratada produziu um maior aumento do $\mathrm{G}^{*}$, para ambos os ligantes asfálticos, seguido do cimento Portland e do pó calcário.

Tabela 5: Resultados dos ensaios no Reômetro de Cisalhamento Dinâmico

\begin{tabular}{|c|c|c|c|c|c|}
\hline \multirow{2}{*}{$f / a$} & \multirow{2}{*}{ Tipo de Fíler } & \multicolumn{2}{|c|}{ G* (MPa) } & \multicolumn{2}{|c|}{$\delta\left({ }^{\circ}\right)$} \\
\hline & & CAP50/70 & CAP $85 / 100$ & CAP50/70 & CAP $85 / 100$ \\
\hline 0,0 & \multirow{3}{*}{ cimento Portland } & $2.34 \mathrm{E}+05$ & $1.14 \mathrm{E}+05$ & 75 & 80 \\
\hline 0,6 & & $6.83 \mathrm{E}+05$ & $3.25 \mathrm{E}+05$ & 73 & 73 \\
\hline 1,2 & & $1.82 \mathrm{E}+06$ & $5.55 \mathrm{E}+05$ & 71 & 77 \\
\hline 0,0 & \multirow{3}{*}{ pó calcário } & $2.34 \mathrm{E}+05$ & $1.14 \mathrm{E}+05$ & 75 & 80 \\
\hline 0,6 & & $7.21 \mathrm{E}+05$ & $3.02 \mathrm{E}+05$ & 73 & 79 \\
\hline 1,2 & & $9.56 \mathrm{E}+05$ & $5.15 \mathrm{E}+05$ & 72 & 78 \\
\hline 0,0 & \multirow{2}{*}{ cal hidratada } & $2.34 \mathrm{E}+05$ & $1.14 \mathrm{E}+05$ & 75 & 80 \\
\hline 0,6 & & $1.01 \mathrm{E}+06$ & $5.42 \mathrm{E}+05$ & 71 & 76 \\
\hline
\end{tabular}

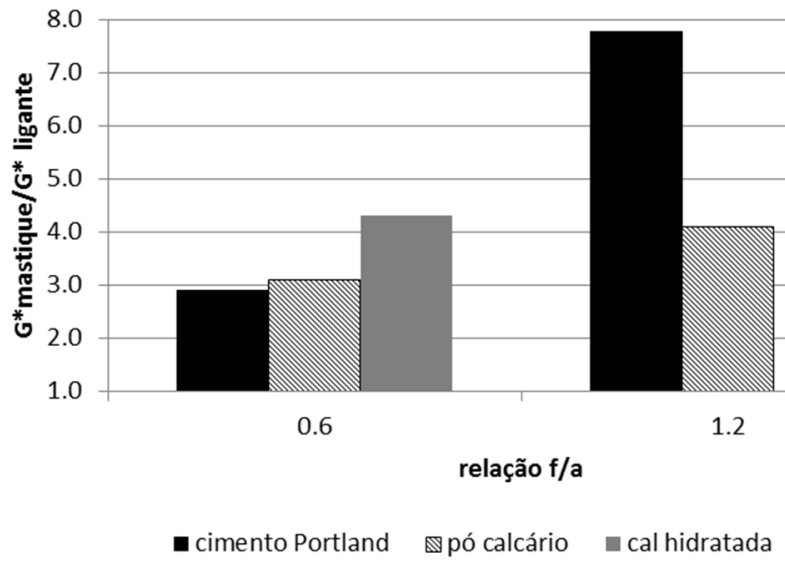

(a)

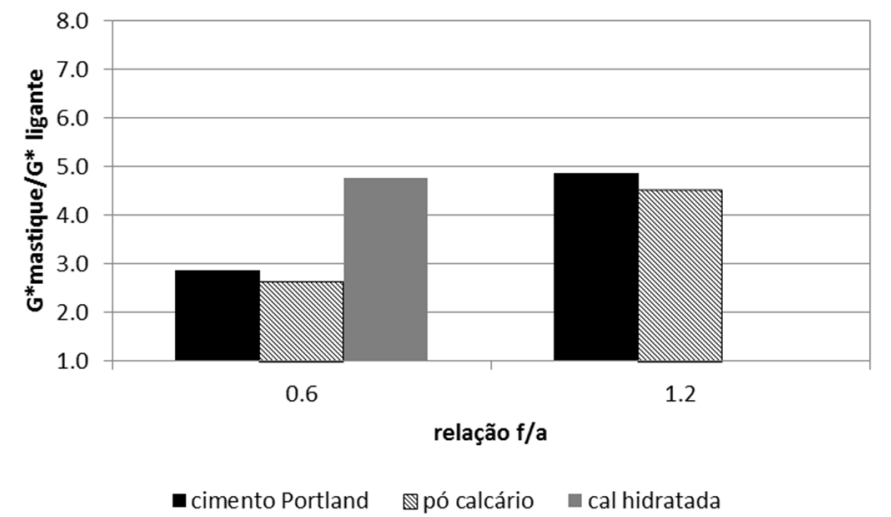

(b)

Figura 7. Aumento do módulo complexo $\left(G^{*}\right)$ em função do tipo de fíler e da relação f/a, para mástiques compostos com: (a) CAP 50/70 e (b) CAP 85/100 
Os mástiques com o CAP 50/70 apresentaram maior aumento de $\mathrm{G}^{*}$ que os mástiques com o CAP 85/100. Com o CAP 50/70, a adição de cal hidratada produziu mástiques mais rígidos e com o CAP 85/100 o maior valor de $G^{*}$ foi obtido utilizando-se o cimento Portland, numa evidência de que o comportamento do mástique também depende da interação entre o fíler mineral e o ligante asfáltico (Ishai e Craus, 1977). Em relação ao ângulo de fase ( $\delta$ ), há diminuição com o aumento do teor de fíler, ou seja, maiores teores de fíler apresentam um aumento na elasticidade do mástique, como também foi observado por Bardini (2013).

\subsection{Reômetro de Viga a Flexão (BBR)}

As Tabelas 6 e 7 mostram os resultados dos ensaios no BBR (rigidez e taxa de relaxação), realizados na temperatura de $-12^{\circ} \mathrm{C}$. A adição do fíler mineral aumenta os valores de rigidez do ligante asfáltico e esse aumento é maior quando maior o teor de fíler. Isso significa que a utilização de altos teores de fíler diminui a capacidade do ligante de resistir ao trincamento térmico. Como notado para o ensaio de energia de fratura, a maior rigidez foi obtida quando a cal hidratada foi utilizada, para ambos os ligantes asfálticos. Todavia, os mástiques asfálticos preparados com cimento Portland e CAP 85/100 apresentaram alta rigidez, quase tão alta quanto às obtidas com cal hidratada e com o pó calcário.

Tabela 6: Resultados de Módulo de Rigidez - S(60)

\begin{tabular}{|c|c|c|c|c|}
\hline \multirow{2}{*}{$\begin{array}{c}\text { Tipo de } \\
\text { Ligante Asfáltico }\end{array}$} & \multirow{2}{*}{ Tipo de Fíler } & \multirow{2}{*}{$f / a$} & \multicolumn{2}{|c|}{ Envelhecimento } \\
\hline & & & Convencional & Modificado \\
\hline \multirow{8}{*}{ CAP 50/70 } & \multirow{3}{*}{ pó calcário } & 0,0 & 189 & 205 \\
\hline & & 0,6 & 328 & 350 \\
\hline & & 1,2 & 620 & 683 \\
\hline & \multirow{3}{*}{ cimento Portland } & 0,0 & 189 & 205 \\
\hline & & 0,6 & 447 & 350 \\
\hline & & 1,2 & 626 & 678 \\
\hline & \multirow{2}{*}{ cal hidratada } & 0,0 & 189 & 205 \\
\hline & & 0,6 & 455 & 518 \\
\hline \multirow{8}{*}{ CAP $85 / 100$} & \multirow{3}{*}{ pó calcário } & 0,0 & 123 & 136 \\
\hline & & 0,6 & 272 & 260 \\
\hline & & 1,2 & 468 & 448 \\
\hline & \multirow{3}{*}{ cimento Portland } & 0,0 & 123 & 136 \\
\hline & & 0,6 & 272 & 271 \\
\hline & & 1,2 & 468 & 463 \\
\hline & \multirow{2}{*}{ cal hidratada } & 0,0 & 123 & 136 \\
\hline & & 0,6 & 276 & 389 \\
\hline
\end{tabular}

0 aumento do teor de fíler diminui a taxa de relaxação. Assim, altos teores de fíler diminuem a eficiência da dissipação das tensões desenvolvidas durante a contração do ligante asfáltico, quando a temperatura do pavimento cai abruptamente, aumentando o risco de trincamento. Os mástiques compostos com a cal hidratada apresentaram os menores valores de $\mathrm{m}(60)$, para ambos os ligantes asfálticos. 0 comportamento dos mástiques compostos com cimento Portland depende do ligante asfáltico: combinado ao CAP 50/70, apresentaram valores de m(60) similares aos da cal hidratada; combinados ao CAP 85/100, apresentaram os maiores valores de m(60), quando comparados aos fileres de cal hidratada e pó calcário.

Tabela 7: Resultados de Taxa de Relaxação - m(60)

\begin{tabular}{|c|c|c|c|c|}
\hline \multirow{2}{*}{ Ligante Asfáltico } & \multirow{2}{*}{ Tipo de Fíler } & \multirow{2}{*}{$f / a$} & \multicolumn{2}{|c|}{ Envelhecimento } \\
\hline & & & Convencional & Modificado \\
\hline \multirow{3}{*}{ CAP 50/70 } & \multirow{3}{*}{ pó calcário } & 0,0 & 0,337 & 0,335 \\
\hline & & 0,6 & 0,322 & 0,321 \\
\hline & & 1,2 & 0,307 & 0,305 \\
\hline
\end{tabular}


Tabela 7: Resultados de Taxa de Relaxação - m(60) (Continuação)

\begin{tabular}{|c|c|c|c|c|}
\hline \multirow{2}{*}{ Ligante Asfáltico } & \multirow{2}{*}{ Tipo de Fíler } & \multirow[b]{2}{*}{ f/a } & \multicolumn{2}{|c|}{ Envelhecimento } \\
\hline & & & Convencional & Modificado \\
\hline \multirow{5}{*}{ CAP 50/70 } & \multirow{3}{*}{ cimento Portland } & 0,0 & 0,337 & 0,335 \\
\hline & & 0,6 & 0,315 & 0,321 \\
\hline & & 1,2 & 0,307 & 0,305 \\
\hline & \multirow{2}{*}{ cal hidratada } & 0,0 & 0,337 & 0,335 \\
\hline & & 0,6 & 0,314 & 0,311 \\
\hline \multirow{8}{*}{ CAP 85/100 } & \multirow{3}{*}{ pó calcário } & 0,0 & 0,349 & 0,346 \\
\hline & & 0,6 & 0,327 & 0,328 \\
\hline & & 1,2 & 0,314 & 0,315 \\
\hline & \multirow{3}{*}{ cimento Portland } & 0,0 & 0,349 & 0,346 \\
\hline & & 0,6 & 0,330 & 0,327 \\
\hline & & 1,2 & 0,317 & 0,314 \\
\hline & \multirow{2}{*}{ cal hidratada } & 0,0 & 0,349 & 0,346 \\
\hline & & 0,6 & 0,328 & 0,318 \\
\hline
\end{tabular}

\subsection{Correlação Entre Energia de Fratura e os Parâmetros Reológicos}

A Figura 8 mostra a correlação entre a energia de fratura e o módulo complexo dos materiais não envelhecidos. Pode-se notar que a energia de fratura diminui com o aumento de $G^{*}$. A adição de maiores quantidades de fíler diminui a resistência ao trincamento em temperaturas intermediárias (diminuição da energia de fratura) e torna o ligante asfáltico mais rígido (aumento do $\mathrm{G}^{*}$ ).

A Figura 9 mostra a correlação entre a energia de fratura e o ângulo de fase. A energia de fratura aumenta com o aumento do ângulo de fase, sendo que a elasticidade aumenta com a adição de fíler, o que é observado pela redução do ângulo de fase. Constata-se que, como a diminuição do ângulo de fase com o aumento do teor de fíler é pequena, ou seja, o efeito da relação f/a sobre a elasticidade é pouco significativo, a correlação é mais baixa que para o módulo complexo.

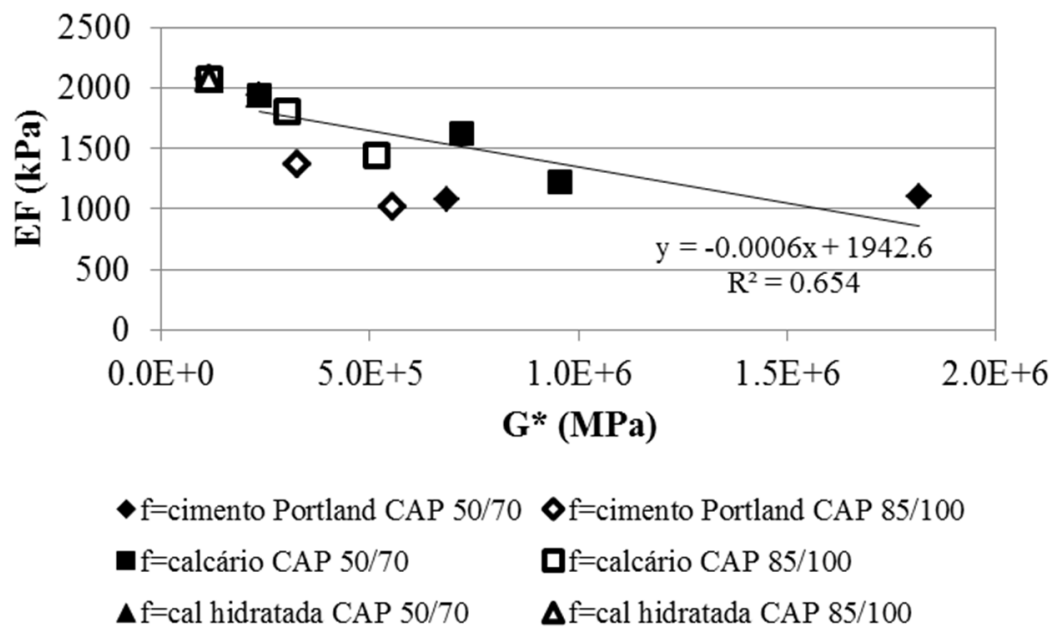

Figura 8: Energia de Fratura (EF) versus Módulo Complexo (G*), para mástiques não envelhecidos

A Figura 10 mostra a relação entre a energia de fratura e a rigidez a baixa temperatura para mástiques envelhecidos, tanto para o envelhecimento convencional (a) como para o procedimento modificado (b). A presença de maiores quantidades de fíler no mástique asfáltico reduz a resistência ao trincamento em temperaturas intermediárias (diminuição da energia de fratura) e também diminui a resistência ao trin $\neg$ camento térmico (aumento do $S(60)$ ). 


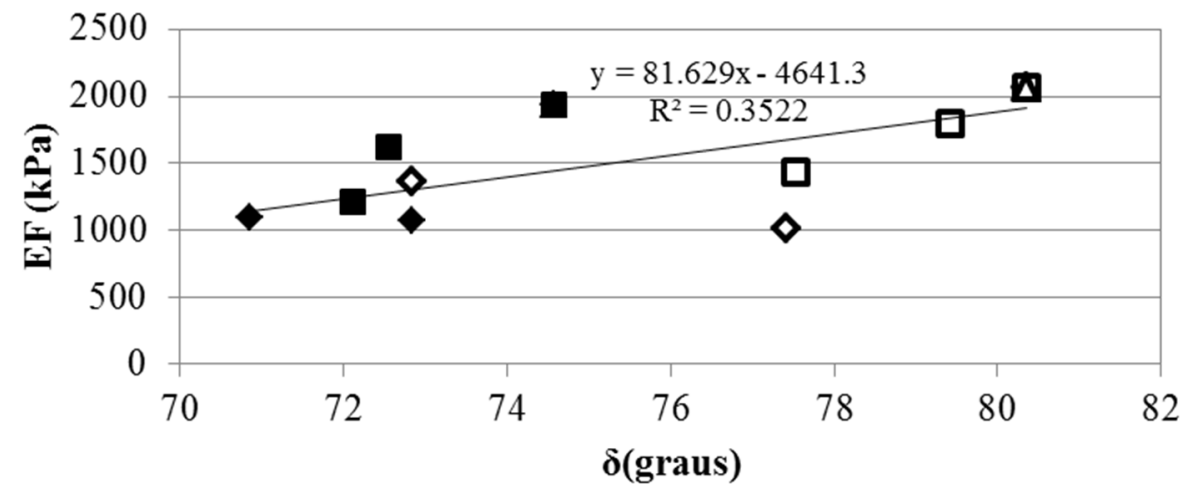

$\diamond \mathrm{f}=$ cimento Portland CAP 50/70 $\diamond \mathrm{f}=$ cimento Portland CAP 85/100

- $\mathrm{f}=$ calcário CAP 50/70 $\mathrm{f}=$ calcário CAP 85/100

$\boldsymbol{\Delta} \mathrm{f}=$ cal hidratada CAP 50/70 $\quad \boldsymbol{\Delta} \mathrm{f}=$ cal hidratada CAP 85/100

Figura 9: Energia de Fratura (EF) versus Ângulo de Fase (ס), para mástiques não envelhecidos

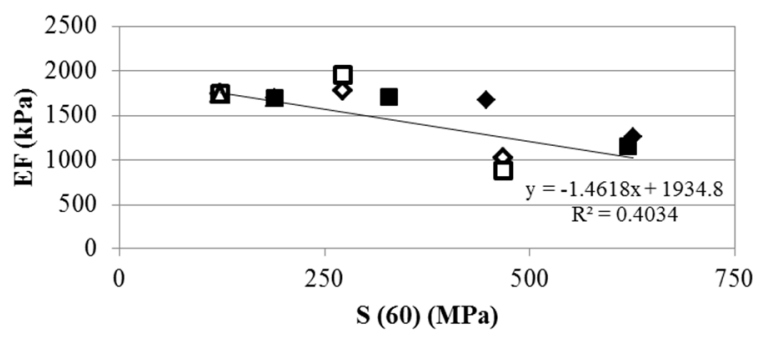

४f-cimento Portland CAP 50/70 \f=cimento Portland CAP 85/100

- $\mathrm{f}$ =calcário CAP 50/70 $\quad$ वf=calcário CAP 85/100

$\boldsymbol{\Delta} \mathrm{f}=\mathrm{cal}$ hidratada CAP 50/70 $\quad \boldsymbol{\Delta} \mathrm{f}=$ cal hidratada CAP $85 / 100$

(a)

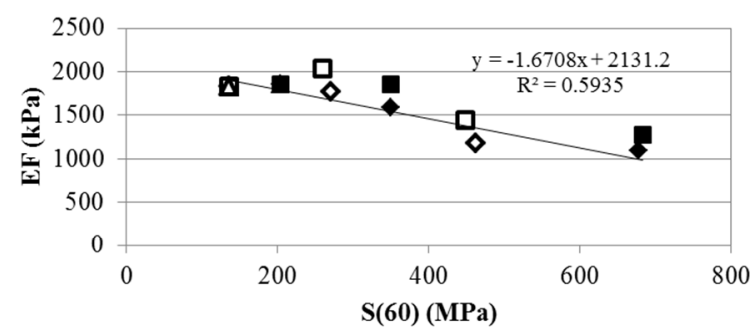

-f=cimento Portland CAP 50/70 $\diamond f=$ =cimento Portland CAP 85/100

- $\mathrm{f}=$ =calcário CAP 50/70 $\quad$ af=calcário CAP 85/100

$\Delta \mathrm{f}=$ cal hidratada CAP 50/70 $\quad \boldsymbol{\Delta} \mathrm{f}=$ cal hidratada CAP 85/100

(b)

Figura 10: Energia de Fratura (EF) em função da Rigidez [S(60)] e envelhecimento: (a) convencional; (b) modificado

A Figura 11 mostra a correlação entre a energia de fratura e a taxa de relaxação, tanto para o envelhecimento convencional (a) como para o procedimento modificado (b). 0 aumento do teor de fíler diminui a eficiência na dissipação da tensão acumulada durante a contração do ligante asfáltico, ou seja, diminui a taxa de relaxação, o que pode representar um dos fatores responsáveis pela diminuição da resistência ao trincamento a baixas temperaturas.

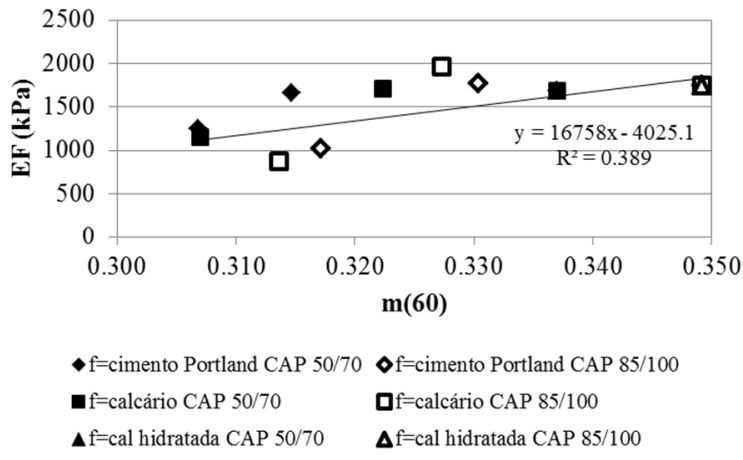

(a)

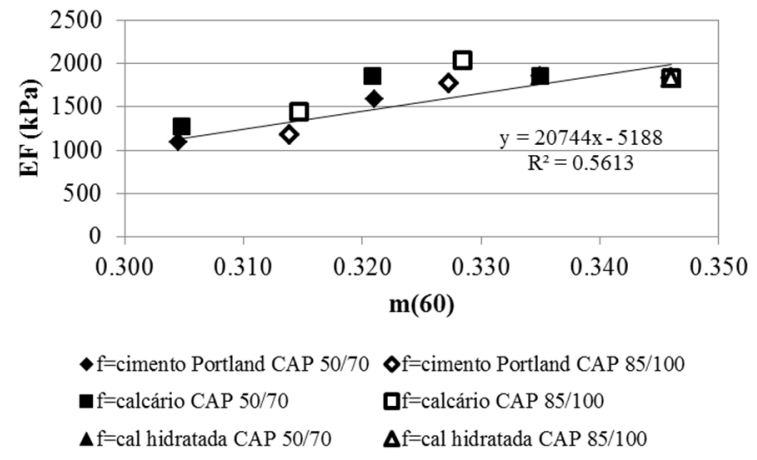

(b)

Figura 11: Energia de Fratura (EF) em função da Taxa de Relaxação e envelhecimento: (a) convencional; (b) modificado 


\section{CONCLUSÕES}

Um novo ensaio para determinação da energia de fratura de ligantes asfálticos foi desenvolvido na Universidade da Flórida (BFE) e utilizado neste trabalho para a avaliação de mástiques asfálticos compostos por diferentes fíleres minerais - cimento Portland, pós calcário e cal hidratada, diferentes ligantes asfálticos (CAP 50/70 e CAP 85/100) e diferentes relações fíler/asfalto (f/a = 0,6 e 1,2 para Cimento e calcário e 0,3 e 0,6 para cal).

Os resultados obtidos mostram que a adição de fíler ao ligante asfáltico diminui a energia de fratura, sendo que essa queda é maior quando a relação f/a aumenta. Assim, verificou-se que há uma redução na resistência ao trincamento de misturas asfálticas, na extensão em se correlaciona com a energia de fratura do ensaio, ou seja, em temperaturas intermediárias, para os fileres estudados. A cal hidratada é o tipo fíler que mais reduz a energia de fratura, mesmo para baixas relações fíler/asfalto e para os dois tipos de ligante asfáltico analisados.

Em relação ao efeito do envelhecimento, conclui-se que os mástiques asfálticos são menos sensíveis ao envelhecimento, o que poder-se-ia traduzir como um ganho na vida útil do revestimento asfáltico antes do surgimento do trincamento por fadiga. E, finalmente, os resultados mostram que a energia de fratura pode ser relacionada com os parâmetros reológicos (módulo complexo, ângulo de fase, rigidez e módulo de relaxação), mas todas as correlações são tênues, reforçando a hipótese de que pode-se obter uma melhor inferência sobre o desempenho à fadiga de uma mistura asfáltica ao se usar a energia de fratura em conjunto com outras propriedades fundamentais tradicionais.

\section{AGRADECIMENTOS}

À CAPES (Coordenação de Aperfeiçoamento de Pessoal de Nível Superior) pela bolsa de doutorado concedida aos dois primeiros autores deste trabalho e pela concessão da bolsas do Programa de Doutorado no País com Estágio no Exterior à primeira autora.

\section{REFERÊNCIAS}

Anderson, D.A. e R. Dongre (1995) The SHRP Direct Tension Specification Test - Its Development and Use. Physical Properties of Asphalt Cement Binders, J.C. Hardin, Ed. ASTM Special Technical Publication 1241. American Society for Testing and Materials, Philadelphia, PA, p. 51-66.

Anderson, D. A.; L. Lapalu; M.O. Marasteanu; Y. M. L. Hir; J. P. Planche e D. Martin (2001) Low-temperature thermal cracking of asphalt binders as ranked by strength and fracture properties, Journal of the Transportation Research Board, v. 1766, p.1-6.

Bahia, H.; H. Wen e C.M. Johnson (2010) Developments in intermediate temperature binder specifications. Transportation Research Circular, E-C147, December, p.25-33.

Hoare, T. R. e S.A. Hesp (2000) Low-temperature fracture testing of asphalt binders, Journal of the Transportation Research Board, v. 1728, p.36-42.

Huang, S. C.; J. C. Petersen; R. E. Robertson e J. F. Branthaver (2001) Effect of Hydrated Lime on the Long-Term Oxidative Aging Characteristics of Asphalt. Transportation Research Record

Huang, S.C.; J. C. Petersen; R. E. Robertson e J. F. Branthaver (2002) Effect of hydrated lime on long-term oxidative aging characteristics of asphalt. Transportation Research Record, n. 1810, p. 17-24.

Huang, S. C e M. ZENG (2007) Characterization of aging effect on rheological properties of asphalt-filler systems. International Journal of Pavement Engineering, v. 8, n. 3, p. 213-223

Ishai, I. e J. Craus (1977) Effects of the Filler on Aggregate-Bitumen Adhesion Properties in Bituminous Mixtures. Proceedings of the Association of Asphalt Paving Technologists, v. 46, p. 228-258.

Kim, Y.R.; D.N. LITTLE e I. Song (2003) Effect of mineral fillers on fatigue resistance and fundamental material characteristics - mechanic evaluation. Transportation Research Record, no.1832, Transportation Research Board of the National Academies Washington, D.C., p. 1-8.

Koh, C. e R. Roque (2010) Use of Nonuniform Stress-State Tests to Determine Fracture Energy of Asphalt Mixtures Accurately. Transportation Research Record: Journal of the Transportation Research Board, No. 2181, Transportation Research Board of the National Academies, Washington, D.C., p. 55-66.

Pinilla, A. (1965) O sistema fíler-betume, algumas considerações sobre sua importância nas misturas densas. Conselho Nacional de Pesquisa. Instituto de Pesquisas Rodoviárias.

Ponniah, J.E.; R.A. Cullen e S. A. Hesp (1996) Fracture energy specifications for modified asphalts. Preprints of Papers, Journal Volume 41, Journal Issue 4, Conference 212, National meeting of the American Chemical Society (ACS), Orlando, FL, USA, p. 25-30 August 1996.

Romeo, E. (2008) Measurement and Prediction of Fundamental Tensile Failure Limits of Hot Mix Asphalt (HMA). Doctoral dissertation. University of Florida, Gainesville, FL. 
Roque, R.; G. Lopp; W. Li e T. Niu (2009) Evaluation of Hybrid Binder Use In Surface Mixtures In Florida. Final report for FDOT BD-545 Contract, University of Florida, Gainesville, FL.

Roque, R.; T. Niu e G. Loop (2012) Development of a Binder Fracture Test to Determine Fracture Energy. Final report for FDOT BDK-75-977-27 Contract, University of Florida, Gainesville, FL.

Walker, Dwight (2017) Refining Superpave asphalt binder characterization. Asphalt: The Magazine of the Asphalt Institute. Nota técnica. Disponível em: http://asphaltmagazine.com/refining-superpave-asphalt-binder-characterization/. (Acessado em 01 de junho de 2017) 